\title{
Componente Curricular ${ }^{1}$ de Modelagem Matemática: um Olhar para as Instituições Universitárias Estaduais do Paraná
}

\author{
Wellington Piveta Oliveira \\ Tiago Emanuel Klüber
}

\begin{abstract}
RESUMO
Neste estudo refletimos sobre alguns aspectos que emergiram da nossa pesquisa de Mestrado, ao investigarmos sobre a presença da Modelagem Matemática como componente curricular nas instituições universitárias estaduais paranaenses. A pesquisa de abordagem qualitativa, fenomenológico-hermenêutica, interrogou: "O que se revela sobre a presença da Modelagem Matemática na Educação Matemática, nos cursos de Licenciaturas em Matemática, das instituições universitárias estaduais do Paraná?". Admitindo esse movimento, ao focarmos os planos de ensino dessas componentes e, os depoimentos dos docentes-formadores, emergiram seis Núcleos de sentido que se articulam, se complementam e revelam significados no contexto da investigação. Em particular, o "Núcleo II - Compreensões sobre as disciplinas de Modelagem Matemática" indica compreensões sobre essa presença, assim como se alinha à temática de pesquisa que temos assumido - formação de professores em Modelagem - por isso, apresentá-lo, mostrou-se como uma possibilidade para refletir e refinar nossas compreensões sobre essa temática. O estudo mostra que as componentes de Modelagem têm se configurado de modo episódico no âmbito dos cursos de Licenciatura em Matemática e, ensejou um debate acerca de sua existência como componente ou, como estratégia metodológica que deveria perpassar todo o curso, desvelando que uma reestruturação da Licenciatura poderia implicar o favorecimento de práticas pedagógicas com essas tendências em Educação Matemática.
\end{abstract}

Palavras-chave: Pesquisa Educacional. Componente Curricular. Licenciatura em Matemática.

\footnotetext{
${ }^{1}$ A fim de mantermos a originalidade da escrita da Dissertação de Mestrado, em alguns momentos deste texto o termo "componente" está redigido "disciplina".
}

\footnotetext{
Wellington Piveta Oliveira é Mestre em Educação. Atualmente, é Doutorando no Programa de Pós-Graduação em Educação para a Ciência e a Matemática da Universidade Estadual de Maringá - UEM. Endereço para correspondência: Av. Colombo 5790, Jd. Universitário, 87020-900, Maringá/PR.

E-mail: wellingtonmat09@hotmail.com

Tiago Emanuel Klüber é Doutor em Educação Científica e Tecnológica pela Universidade Federal de Santa Catarina - UFSC. Atualmente, é professor adjunto na Universidade Estadual do Oeste do Paraná - UNIOESTE. Programa de Pós-Graduação em Educação em Ciências e Educação Matemática. Endereço: Departamento de Matemática, Rua Universitária, 2069, Jardim Universitário, 85819-110, Cascavel/PR, Brasil.

E-mail: tiagokluber@gmail.com

Recebido para publicação em 20 jul. 2018. Aceito, após revisão, em 3 set. 2018.

DOI: https://doi.org/10.17648/acta.scientiae.v20iss5id4582.
}

Acta Scientiae v. 20

n.5

p.813-830

set./out. 2018 


\title{
Curricular Component of Mathematical Modeling: A Look at the State University Institutions of Paraná
}

\begin{abstract}
In this study we reflect on some aspects that emerged from our Master's research, when investigating the presence of Mathematical Modeling as a curricular component in the state university institutions of Paraná. The qualitative-phenomenological-hermeneutic research questioned: "What is revealed about the presence of Mathematical Modeling in Mathematics Education, in the Mathematics Degree courses, of the state university institutions of Paraná?" Admitting this movement, by focusing on the teaching plans of these components, and the testimonies of the teacher-trainers, six nuclei of meaning have emerged that are articulated, complement each other and reveal meanings in the research context. In particular, "Core II - Understanding Mathematics Modeling disciplines" indicate understandings about this presence, as well as, it is aligned with the research topic that we have assumed - teacher training in Modeling - for that reason, presenting it, showed As a possibility to reflect and refine our understandings on this subject. The study shows that the components of Modeling have been configured in an episodic way in the scope of the courses of Degree in Mathematics and, gave rise to a debate about its existence as a component or as a methodological strategy that should permeate the whole course, revealing that a restructuring of the Degree could imply the favoring of pedagogical practices with these tendencies in Mathematics Education.
\end{abstract}

Keywords: Educational Research. Curricular Component. Degree in Mathematics.

\section{DANDO SENTIDO À INVESTIGAÇÃO}

As discussões sobre Modelagem Matemática na Educação Matemática² vêm sendo abordadas por pesquisadores brasileiros desde o final da década de 1970 (Barbosa, 2011). A partir de então, as reflexões passaram a fazer parte das atividades práticas de sala de aula, com enfoque no ensino e aprendizagem dos conteúdos matemáticos e ainda, no âmbito acadêmico, no tocante à pesquisa, a fim de investigar suas potencialidades e limitações, bem como, refletir epistemologicamente sobre sua gênese e características. Esses debates emergiram da necessidade que pesquisadores sentiram de refletir sobre o caráter prático da Modelagem, dada à essência de sua natureza, conforme apontou Klüber (2016, p.23) que “[...] está endereçada, direta ou indiretamente, às práticas de ensino e de aprendizagem da Matemática, portanto, admitindo a inseparável dimensão prática de toda e qualquer pesquisa educacional".

Mais recentemente, estudos sobre a Modelagem revelaram que ela se configurou como uma tendência relevante para a Educação Matemática, dada ao seu reconhecimento como tendência metodológica em documentos oficiais, como, por exemplo, no Estado do Paraná, nas Diretrizes Curriculares Estaduais - DCE.

Essa relevância remete também a sua expressividade nos eventos científicos, consolidando-os como espaços importantes para discussões, tendo em vista, o

\footnotetext{
${ }^{2}$ Para fins textuais, utilizaremos apenas Modelagem quando referirmos a Modelagem Matemática na Educação Matemática.
} 
amadurecimento dos debates e a configuração de agendas de pesquisa. Um evento que se destaca e de âmbito nacional é a Conferência Nacional sobre Modelagem na Educação Matemática $\left(\mathrm{CNMEM}^{3}\right)$, outro de caráter regional, o Encontro Paranaense de Modelagem na Educação Matemática (EPMEM), além de outros ainda, da Educação Matemática que admitem a Modelagem como linha de investigação.

Articulada a essa expressividade, também destacamos um número significativo de produções sobre Modelagem, como artigos em periódicos, dissertações e teses, e sua representatividade no âmbito da Sociedade Brasileira de Educação Matemática (SBEM), com um Grupo de Trabalho específico de Modelagem Matemática (GT-10) (Klüber, 2012a).

Todo esse escopo ensejou a afirmação da existência de uma comunidade de pesquisadores que pesquisa sobre Modelagem (Barbosa, 2007), que ao nosso entendimento se configura por um debate intra e intercoletivo de ideias sobre ela (Oliveira, 2016a), (Klüber, 2016), o que impulsiona essa comunidade na busca por uma identidade como campo de pesquisa e de práticas no contexto da Educação Matemática.

Os debates nesse campo têm assumido diferentes objetos e/ou temáticas de investigação, por exemplo, os pesquisadores têm voltado seus olhares para “[...] análise de materiais didáticos [...], práticas pedagógicas com a Modelagem, estudos sobre os elementos que [a] compõem [...] a análise de outras pesquisas em Modelagem (metaestudos), [...] aspectos teóricos e epistemológicos da Modelagem [...]" (Klüber, et al., 2015, p.90, inserção nossa) e, mais recentemente, na nona edição da CNMEM, realizada na Universidade Federal de São Carlos (UFSCar), São Carlos - SP, foi afirmado que "[...] a Formação de Professores, no contexto da Modelagem Matemática, em particular, é uma tendência que está em destaque desde sempre, mas que precisa ser melhor investigada [...]" (Malheiros, et al., 2015, p.5), tendo em vista a sua chegada às salas de aula, reconhecendo, assim, a relevância dessa temática para o campo de pesquisa e de debate nessa comunidade.

Dessa perspectiva e pensando nas contribuições para esse debate, assim como, nas inquietações particulares enquanto pesquisadores, é que nossa investigação de Mestrado foi estruturada, admitindo a presença da Modelagem em componentes curriculares específicas nas licenciaturas em Matemática das instituições universitárias estaduais do Paraná, como fenômeno de pesquisa. Sob a interrogação: "O que se revela sobre a presença da Modelagem Matemática na Educação Matemática, nos cursos de Licenciaturas em Matemática, das instituições universitárias estaduais do Paraná? ", voltamos os nossos olhares para a formação inicial de professores de Matemática (Oliveira, 2016b).

Foi considerando, portanto, o movimento fenomenológico-hermenêutico de investigação, que ao estabelecermos as convergências entre as unidades de significados

\footnotetext{
${ }^{3}$ A Conferência é organizada bienalmente, desde 1999. AX CNMEM em 2017 foi sediada na Universidade Estadual de Maringá, organizada pelo grupo de estudos e pesquisas, Grupo Interdisciplinar de Estudos em Modelagem na Educação Matemática (GIEMEM). A XI CNMEM, em 2019, será sediada na Universidade Federal de Minas Gerais, em Belo Horizonte, Minas Gerais - MG.
} 
que destacamos à luz da interrogação de pesquisa, emergiram seis Núcleos de Sentido, a saber: 1) Sobre as referências utilizadas nas disciplinas; 2) Compreensões sobre as disciplinas de Modelagem Matemática; 3) Apontamentos teóricos sobre Modelagem Matemática; 4) Sobre o desenvolvimento das disciplinas de Modelagem Matemática; 5) Modelagem Matemática e o Estágio Supervisionado; e, 6) O sentido da Modelagem atribuído à formação. Cada um deles expressou significados particulares, mas que em vários momentos se articularam, dando sentido à pesquisa e tematizando, portanto, sobre a presença da Modelagem nos cursos de Licenciatura em Matemática.

$\mathrm{Na}$ tentativa de refinarmos as compreensões sobre essa presença, mais especificamente, sobre as componentes curriculares de Modelagem, sintetizamos o debate mais amplo, nesse texto, com a pretensão de apresentarmos as reflexões emergentes do movimento de interrogar os sentidos que se expressaram, em particular, do "Núcleo II - Compreensões sobre as disciplinas de Modelagem Matemática”, como resultado de esse olhar analítico.

Para que possamos delinear essas compreensões, explicitaremos, primeiramente, a metodologia e os procedimentos que foram adotados para realização da pesquisa expressa como nossa dissertação e que subsidiam agora, os desvelamentos sobre as componentes de Modelagem que aqui apresentaremos.

\section{SOBRE O MODO COMO PROCEDEMOS À PESQUISA: VISÃO E PROCEDIMENTOS}

Admitimos a pesquisa qualitativa segundo a visão fenomenológica. Segundo a literatura, essa visão de pesquisa consiste num movimento próprio “[...] de trabalhar com sentidos e significados que não se dão em si, mas que vão se constituindo e se mostrando em diferentes modos, de acordo com a perspectiva do olhar e na temporalidade histórica de suas durações [...]" (Bicudo, 2011, p.41). Trabalhar com sentidos e significados que vão se constituindo e se mostrando, consiste no movimento de desvelar o fenômeno com a intencionalidade de compreendê-lo em suas particularidades, suspendendo as impressões primeiras que dele se manifestam e ir além, transcendendo-o em direção à sua essência (Bicudo, 2011).

Em outras palavras, a postura que adotamos permitiu-nos " [...] circular em torno do que se deseja compreender, não se preocupando única e/ou aprioristicamente com princípios, leis e generalizações, mas voltando o olhar à qualidade, aos elementos que sejam significativos para o observador-investigador" (Garnica, 1997, p.111), no contexto de suas manifestações, nesse sentido, a presença da Modelagem no âmbito da formação inicial de professores, nas licenciaturas em Matemática das instituições universitárias estaduais do Estado do Paraná.

Nessa abordagem, estabelecer uma interrogação de pesquisa se mostrou pertinente ao movimento que efetuamos, por destacar-se como "[...] um pano de fundo onde as perguntas do pesquisador encontram seu solo, fazendo sentido [...]. [Assim] ela se constitui 
no norte que dá direção aos procedimentos da pesquisa" (Bicudo, 2011, p.23, inserção nossa). Desse modo, considerando sua relevância no âmbito da pesquisa fenomenológica, esse movimento nos conduziu a sistematizá-la como: "O que se revela sobre a presença da Modelagem Matemática na Educação Matemática, nos cursos de Licenciaturas em Matemática, das instituições universitárias estaduais do Paraná?”, por entendermos que ela se mostra como uma tradução ao nosso problema de pesquisa.

Considerando, portanto, que a interrogação nos orienta dando-nos um norte aos procedimentos de pesquisa, o fato de interrogarmos a própria interrogação, nos conduziu a olharmos para o contexto da formação inicial de professores de Matemática, primeiramente, para que então pudéssemos estabelecer um debate sobre a presença da Modelagem nesse contexto. Desse modo, questionamentos do tipo, "Mas, de quais cursos? O que consideraremos por essa presença?”, nos conduziram a mapearmos quais instituições de ensino público e superior ofertavam o curso de Licenciatura em Matemática no Estado do Paraná e, respondendo a esses questionamentos, quais desses cursos ofertavam a Modelagem como componente curricular.

A "Figura 1" a seguir, pode ilustrar o mapeamento que realizamos, sistematicamente, apontando os municípios em que há oferta de cursos de Licenciatura em Matemática e, respectivamente, a componente curricular de Modelagem.

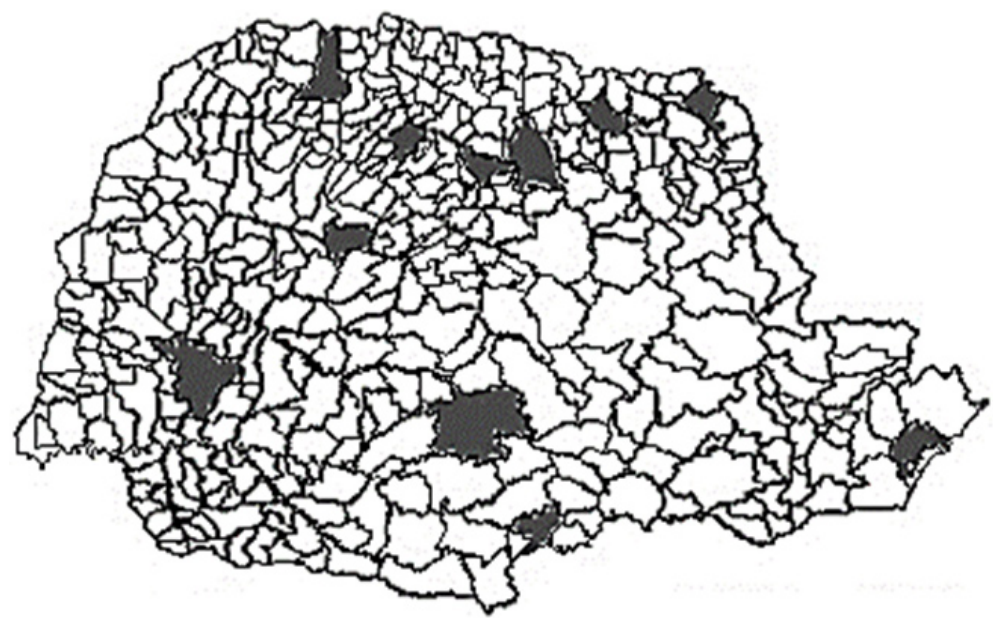

Figura 1. Municípios em que se situam as universidades estaduais que ofertam a Modelagem como componente curricular.

Feito esse levantamento, ele nos mostrou que as componentes curriculares de Modelagem nas universidades estaduais no Estado do Paraná, estavam congregadas em quatro universidades, localizadas em oito campi diferentes. Localizadas essas instituições, convidamos os docentes-formadores que estavam vinculados a elas e que ministravam a componente curricular de Modelagem para fazerem parte da nossa pesquisa. Isso porque, dentre as possibilidades de manifestação do fenômeno, a recolha de depoimentos dos 
docentes-formadores e a análise dos planos de ensino dessas componentes, se mostraram relevantes à investigação, dada a possibilidade em desvelarmos algumas compreensões sobre a presença da Modelagem com interface na formação de professores.

Feito o convite à oito dos docentes-formadores e após o aceite de todos, agendamos e coletamos os, respectivos depoimentos. Eles pertenciam à Universidade Estadual de Londrina (UEL) (1), Universidade Estadual do Oeste do Paraná (UNIOESTE) (1), Universidade Estadual Norte do Paraná (UENP) (2), e Universidade Estadual do Paraná (UNESPAR) (4). Na ocasião, solicitamos os planos de ensino das componentes curriculares de Modelagem, cuja qual eles ministraram no ano de 2014.

Realizada essa coleta, transcrevemos os depoimentos de cada um dos docentesformadores, reunimos aos planos de ensino fornecidos por eles e, inserimos todos esses documentos escritos no software de análise qualitativa denominado Atlas t.i., em que foi possível destacarmos as unidades de significado. Em linhas gerais, essas unidades consistiram em excertos que foram significativos à interrogação de pesquisa admitida. Após serem destacadas e, num movimento de convergências estabelecido entre elas e, de modo articulado, elas dão visibilidade a emergência de categorias, o que nesse estudo denominamos por Núcleos de sentido (Bicudo, 2011). Conforme já explicitamos na seção anterior, esse movimento ensejou seis Núcleos distintos, porém não independentes.

Considerando que nesse momento, a pretensão em estruturar esse texto esteja em debater aquilo que desvelamos sobre a configuração das componentes curriculares de Modelagem nas Licenciaturas em Matemática das universidades estaduais no Estado do Paraná, mais especificamente, algumas compreensões sobre essas componentes de Modelagem, o empreendido na próxima seção consiste, inicialmente, em uma apresentação descritiva do "Núcleo de Sentido II: Compreensões sobre as disciplinas de Modelagem Matemática”, que se mostrou na pesquisa. Metodologicamente, reunimos os aspectos que se mostraram na primeira redução fenomenológica do fenômeno perseguido.

$\mathrm{Na}$ sequência, fomentamos a hermenêutica, num olhar interpretativo, sobre as componentes curriculares de Modelagem a partir do que se revelou nessa primeira redução. Ao efetuarmos esse debate, transcendemos nossa discussão para a formação inicial de professores em Modelagem, pois, para além de sua presença, de sua configuração como componente, nossos esforços estiveram centrados no solo da formação em Modelagem.

\section{DESCREVENDO MANIFESTAÇÕES SOBRE AS COMPONENTES CURRICULARES DE MODELAGEM: SOBRE OS INVARIANTES DO FENÔMENO}

A discussão que aqui empreendemos se caracteriza pela necessidade de descrevermos o visto sem deixarmos evadir o que se mostra e, sem preenchermos com conteúdos que não lhes dizem respeito. Queremos dizer que conduzidos pelo movimento que efetuamos, ainda que nossa subjetividade no destaque das unidades estivesse presente, essa primeira 
redução, apenas "[...] descreve o movimento dos atos da consciência. Ela se limita a relatar o visto, o sentido, ou seja, a experiência vivida pelo sujeito” (Bicudo, 2011, p.45).

Em outras palavras, apresentamos aqui um texto expresso pela convergência das unidades de significados ${ }^{4}$ que se mostraram relevantes ao focarmos o nosso fenômeno. Assim sendo, o "Núcleo de Sentido II: Compreensões sobre as disciplinas de Modelagem Matemática” mostrou-nos:

- Questões estruturais das componentes nos currículos dos cursos de Licenciatura em Matemática, tais como, carga horária, o ano/série em que ela está inserida na grade e, seus respectivos nomes.

- Os objetivos das componentes curriculares de Modelagem Matemática.

- Alguns focos, segundo as compreensões dos docentes-formadores.

Ao embrenharmo-nos de modo mais atento ao que expressam essas unidades, o estudo nos mostra que a carga horária das componentes curriculares de Modelagem varia de 60 a 144 horas, com desdobramentos teóricos e práticos e, essa carga horária está subdividida em duas, três ou quatro horas/aulas semanais, dependendo do curso em que se situa. Também emergiram aspectos condizentes à sua distribuição, pois, está configurada de modo semestral ou anual; em alguns cursos está alocada no $3^{\circ}$ ano e, em outros no $4^{\circ}$ ano. Em geral, a maior parte da carga horária destinada às componentes de Modelagem nesses cursos é para a realização de atividades de Modelagem, as quais envolvem análises, investigações e a própria elaboração de algumas atividades.

Sobre os nomes das componentes curriculares, elas são intituladas: Modelagem Matemática e a Pesquisa Operacional, Resolução de Problemas e Modelagem Matemática, Introdução à Modelagem Matemática, e, Modelagem Matemática na perspectiva da Educação Matemática. Vale ressaltarmos ainda que elas estiveram centradas sob enfoques diferenciados, conforme mostra-nos a pesquisa.

Sobre esses enfoques, algumas componentes têm enfatizado uma discussão de formação do professor para exercício da docência no Ensino Superior, voltada à Modelagem como aplicação; outras, admitindo como fundamentos a perspectiva da Educação Matemática, sendo esse o foco predominante nos cursos; e, outras ainda, sem privilegiar uma discussão recorrente, focando a Modelagem para o Ensino Fundamental e Médio. Ademais, a componente curricular de Modelagem no âmbito dos cursos, tem se caracterizado como relativamente novas, embora em alguns deles, ela venha ocorrendo desde a oficialização do curso de Licenciatura.

\footnotetext{
${ }^{4} \mathrm{O}$ recorte: "Considerando que a Modelagem é ampla, o professor entende que ela deveria ser mais que uma disciplina e perpassar por outras (as quais fossem possíveis) no contexto da licenciatura", é um exemplo dessas unidades de significados que foram destacadas na pesquisa. Outros exemplos dessas unidades se encontram, explicitamente, na dissertação: Oliveira, W. P. (2016b) Modelagem Matemática nas licenciaturas em Matemática das universidades estaduais do Paraná. (155 f.) Dissertação de mestrado, Educação, Programa de Pós-Graduação em Educação, Universidade Estadual do Oeste do Paraná, Cascavel.
} 
Outras unidades concernentes a esse núcleo expressaram os objetivos, ou seja, sobre aquilo que se espera com a configuração de uma componente curricular de Modelagem inerente à formação, conforme os planos de ensino e os depoimentos dos docentesformadores revelaram. Nesse sentido, a pesquisa indicou que com os futuros professores engajados num ambiente de formação como a componente de Modelagem presente na Licenciatura em Matemática, é esperado que eles compreendam o conceito da Modelagem como uma forma de resolver problemas. No entanto, para que eles possam resolver determinadas situações-problema, os estudantes precisam estabelecer compreensões a partir de análises, construção, e exploração de modelos, privilegiando, quando possível, uma abordagem orientada pelas diferentes concepções de Modelagem, e ainda, delineando uma interpretação crítica sobre o que fora construído.

Ao tornar-se essa prática mais efetiva, também se tem a pretensão de que o futuro professor reconheça, para além das potencialidades da Modelagem, os seus limites enquanto possibilidade metodológica, tendo em vista que os docentes-formadores apontaram que as discussões sobre Modelagem se fundamentam numa abordagem teóricometodológica. Com ênfase no aspecto pragmático da Modelagem, evidenciaram que essas experiências para a formação são fundamentais, pois, atreladas ao conhecimento de como essas coisas funcionam numa prática, só aumentam as chances de os futuros professores incorporarem de fato, essas orientações como proposta na prática pedagógica.

Embora possa parecer deslocado, os docentes-formadores registraram alguns aspectos sobre as componentes curriculares de Modelagem que, de algum modo, se mostraram significativos para estabelecermos compreensões sobre elas. Esses aspectos foram aqui denominados de focos.

O primeiro foco indica certo amadurecimento das componentes, pois, algumas unidades registraram que a componente curricular de Modelagem, em alguns desses cursos, era desenvolvida de forma distinta do que propõe a literatura, mais recentemente. Alguns docentes-formadores registraram que essa carga horária era destinada à realização de outras atividades, por exemplo, a confecção e estudo de sólidos geométricos. Nesse sentido, a Modelagem na perspectiva da Educação Matemática só foi assumida nessas componentes, recentemente, ao passo que os docentes-formadores foram ampliando seus conhecimentos sobre a Modelagem, a partir de orientações e/ou parcerias com outras instituições, registrando, desse modo, uma mudança de perfil do trabalho no âmbito da formação com a componente.

$\mathrm{O}$ segundo foco se volta para lacunas na formação. Essa afirmação expressa $\mathrm{o}$ diálogo dos docentes-formadores quando dizem da insegurança que os professores sentem em desenvolver práticas de Modelagem no contexto da Educação Básica, mesmo que tenham experenciado essa formação em Modelagem como componente curricular na formação inicial, quando acadêmicos. Embora isso possa sinalizar uma inutilidade dessa componente, surgem ressalvas indicando sua relevância para a formação, pois, quando ela é construída de maneira sólida, ou seja, se mostra presente como uma componente, há maiores chances de práticas como a de Modelagem se fazerem presentes nos contextos futuros. Em outras palavras, se a componente é desenvolvida de modo apropriado, abrem- 
se possibilidades para que esse professor desenvolva práticas e/ou atue na formação de outros, se orientando pelas ações formativas que teve como modelo - nesse caso, a prática alinhada à Modelagem Matemática.

Por último, o terceiro foco registrou, de modo mais amplo, a ausência de debate sobre a própria Modelagem, na formação de professores. De um lado, as unidades registraram, especificamente, a ausência de discussões em Modelagem na Formação Continuada no âmbito da universidade, isto é, os docentes-formadores reconheceram a falta de um grupo de estudos/pesquisas que discuta sobre Modelagem. De outro, a ausência registrada é mais abrangente, pois, evidenciaram que ainda é baixo o número de docentes cuja área de formação é a Educação Matemática, bem como, os seus interesses em discutir e compartilharem sobre esse campo de conhecimentos.

Os parágrafos acima se configuraram como descrição do fenômeno manifesto, como abertura ao Núcleo, o qual nos propomos aqui debater. Empreendida essa descrição que já evidencia algumas compreensões sobre a Modelagem configurada como componente curricular nos cursos de Licenciatura em Matemática das instituições universitárias estaduais do Paraná, na próxima seção, dedicamo-nos ao debate, interrogando-a "o que isso revela?", como uma primeira redução, em busca de seus sentidos no contexto da formação de professores em Modelagem.

\section{INTERPRETAÇÕES SOBRE AS MANIFESTAÇÕES DAS COMPONENTES CURRICULARES DE MODELAGEM MATEMÁTICA: UMA HERMENÊUTICA DOS INVARIANTES}

O debate aqui empreendido caracteriza-se pela transcendência dos invariantes descritos na seção anterior. Embora a descrição já revele as vivências com o fenômeno doado na percepção, para a pesquisa qualitativa de abordagem fenomenológica, ela não é suficiente, pois, solicita um "[...] trabalho interpretativo hermenêutico, visando compreender sentido, significado e significação apontado na descrição" (Bicudo, 2011, p.46). Dito de outro modo, essa seção expressa o que é transcendente das nossas experiências com o dito e o descrito, isto é, o debate se estabelece a partir do que se mostrou no movimento descritivo sobre as componentes curriculares de Modelagem, tendo como solo a formação inicial de professores de Matemática.

À luz da interrogação que assumimos na pesquisa de Mestrado, "O que se revela sobre a presença da Modelagem Matemática na Educação Matemática, nos cursos de Licenciaturas em Matemática, das instituições universitárias estaduais do Paraná?", e do descrito anteriormente, a temática nos abriu um horizonte para refletirmos sobre os programas de formação inicial, mais especificamente, a partir das componentes curriculares de Modelagem, conforme a configuração que se mostrou.

Ao focarmos essas componentes, o "Núcleo de Sentido II: Compreensões sobre as disciplinas de Modelagem Matemática”, mostrou-nos inicialmente - a partir da 
carga-horária destinada a elas, de sua configuração, bem como, dos enfoques que a elas têm sido dados, seja na Matemática Aplicada, como se revelaram em dois dos cursos que investigamos, ou na Educação Matemática, como nos demais - o cenário em que a formação em Modelagem tem se desenvolvido durante esses últimos anos. Para nós, essas manifestações indicam o modo pelo qual a formação tem sido conduzida nessas componentes, nas instituições universitárias estaduais do Estado do Paraná. Indica que a formação em Modelagem tem acontecido em curtos espaços de tempo, oportunizando aos estudantes um período breve de envolvimento com a Modelagem. Sobretudo, com conotações e enfoques distintos, quando há evidencias de um debate mais acalorado sobre a perspectiva da formação docente em algumas componentes, do que em outras.

Diante dessa configuração que se mostra, talvez por conta desse curto período, há indícios de que há pouca ou nenhuma interseção dessas componentes com as demais componentes curriculares, confirmando "[...] que os cursos de formação de professores de Matemática ainda são pautados excessivamente no conteúdo específico, perpetuando uma separação entre disciplinas específicas [...]" (Klüber, 2012b, p.71), assim como acontece, geralmente, com outras componentes. Com efeito, essa discussão mais ampla da qual a componente de Modelagem participa, nos faz refletir que essa configuração (em componentes), se mostra como um desafio para a formação do futuro professor dada a dissociação entre os saberes que são produzidos no conjunto dessas componentes, os quais deveriam constituir o programa na totalidade, com suas particularidades e entrelaçamentos. Em geral, fica por conta do futuro professor estabelecer essas relações, isto é, quando há maturidade para isso. Ao focalizarmos a formação do professor nessas condições, ela tende a ser episódica e, por sua vez, fragmentada. Estendendo-nos, se olharmos para o contexto da Licenciatura em Matemática, esses apontamentos parecem fazer sentido, também para as demais tendências e/ou componentes, tanto específicas, quanto pedagógicas, nesses cursos.

Se considerarmos o reflexo da ausência de uma articulação entre os diferentes conhecimentos produzidos em cada um desses contextos, a prática do professor tende a fragilizar-se, dificultando, por exemplo, o reconhecimento de uma harmonia entre o saber pedagógico, o saber-fazer e, o saber porquê, pelo próprio professor, influenciando no seu conhecimento profissional (Garcia, 1999). Não obstante, essas limitações também afetam o contexto da formação em Modelagem, uma vez que ela ocorre nesse cenário. Talvez, ainda de modo mais acentuado, pois, um exemplo que tem sido comum nos relatos de pesquisa em Modelagem que pode exemplificar esse argumento, é a causa de um conflito na própria ação pedagógica do professor em sala de aula, ao tentar conduzir práticas de Modelagem (ingressando-se numa zona de risco). Por assim fazer, com o insucesso da prática, o leva à desistência ou a resistência a novas tentativas, mantendo-se, pelo menos por algum tempo, na zona de conforto (Penteado, 2001).

Convergente ao que estamos discutindo, ao explorarmos a configuração das componentes aqui focadas, fica evidente que a Modelagem, na maioria dos casos, se manifesta apenas nos últimos anos dos cursos, como componente curricular. Desse modo, e, portanto, episódicas, os estudantes podem não ter a oportunidade de envolverem- 
se com ela de modo mais efetivo, durante a formação inicial. Espaço/tempo este, em que poderiam perceber, agendar e estudar sobre os aspectos que emergem da própria experiência teórico-prático-metodológica, com ela.

Para que esse debate pudesse ir tomando corpo, o fato de perquirirmos uma interrogação, algumas indagações ${ }^{5}$ foram emergindo. Essas primeiras reflexões acerca das componentes curriculares de Modelagem nos convidaram, portanto, a olharmos para o contexto da Licenciatura em Matemática e interrogarmos, de modo mais amplo: " $O$ que é isto, a Modelagem configurada na formação inicial de professores?", também como compreensões que emergem sobre as componentes, conforme o Núcleo que nos propomos discutir.

Transcendendo a descrição emergente em direção às respostas para as indagações, ela indicou que alguns cursos têm possibilitando uma vivência pluralista de experiências com a Modelagem, enquanto que em outros, isso parece não acontecer de modo mais efetivo. Essas manifestações nos conduzem a refletir sobre aqueles que estão conduzindo/ orientando a formação dos estudantes sob uma única perspectiva, como, por exemplo, àqueles cursos cujo foco está na Modelagem como método de aplicação da Matemática, muitas vezes, sem interface com o debate dessa tendência no âmbito da Educação Matemática.

Como a pesquisa permite-nos estabelecer um debate sobre o que se revela das componentes de Modelagem em direção à formação possibilitada por elas, entendemos que o futuro professor, fazendo parte desse contexto, certamente, estará à margem das discussões e das ações que podem fazer mais sentido para o trabalho pedagógico com a Modelagem. À luz do que se mostra, o modo como tem sido desenvolvida, a Modelagem pode tornar-se ainda mais desafiante para a prática pedagógica e, esse contexto, pode levá-lo a desenvolver práticas com as quais já está mais habituado, por sentir-se mais seguro e confiante com os resultados. Para nós, talvez reforce as concepções que o futuro professor já possui e, fortalece o desenvolvimento de práticas mais espontâneas, distantes daquelas que poderiam ser planejadas, com um viés mais investigativo.

Em certo sentido, uma formação que, portanto, pode parecer eficiente ao se mostrar como proposta, isto é, uma componente, de todo modo pode mostrar-se ainda, como um empecilho para prática pedagógica com a Modelagem. Não estamos criticando as diferentes abordagens, até porque compreendemos a relevância e o espaço que têm elas na formação do professor, mas, queremos destacar a ausência das práticas na perspectiva da Educação Matemática, vislumbrando a ação pedagógica em sala de aula. Sob esse olhar, entendemos que a própria prática poderá manifestar a ausência de reflexões que a oriente, de modo a atender as necessidades contextuais e da formação específica para o nível em que ela pode se desenvolver, porque o futuro professor não a vivenciou como proposta pedagógica.

\footnotetext{
${ }^{5}$ Não é nossa pretensão responder as perguntas que vão emergindo, mas, optamos por apresentá-las na tentativa de ajudar-nos a ir desnudando a componente e a formação que estamos buscando compreender (Bicudo, 2011), à luz daquilo que se mostrou dos planos de ensino e, da percepção dos docentes-formadores sobre aquilo que eles consideram sobre a Modelagem na Licenciatura.
} 
Dessa perspectiva, a pesquisa nos permite debater sobre a finalidade dos conhecimentos propiciados pelas componentes de Modelagem, pois, conforme a descrição, objetiva-se que os estudantes compreendam o conceito da Modelagem como forma de resolver problemas; que eles analisem, construam e explorem modelos, perpassando por diferentes perspectivas de Modelagem; além de a reconhecerem, para além das potencialidades, os seus limites enquanto tendência metodológica. A indagação que cabe é: "qual a finalidade, isto é, para que essas compreensões?".

Com esses objetivos, entendemos que a formação em Modelagem está planejada sob matizes. Essa ideia revela que o futuro professor tanto pode reconhecer a Modelagem por meio da análise e construção de modelos quanto, ampliar suas experiências formativas a partir da produção de atividades de Modelagem ou utilizar daquelas já disponibilizadas na literatura, para refletir sobre sua proposta teórico-metodológica. Embora sejam ações distintas que possibilitam olhares e experiências diferentes para essa tendência da Educação Matemática, vale ressaltarmos que no contexto dessa investigação, a ideia de produzir atividades e refletir sobre aquelas já disponíveis na literatura, não se manifestou nas duas componentes cujo enfoque está na Modelagem como método de aplicação dos conteúdos.

Ao nosso olhar, esse cenário, mais uma vez, pode ir na contramão do favorecimento de práticas pedagógicas de Modelagem. Essa reflexão nos mostra que ressignificar essas práticas, conforme os pressupostos e objetivos elencados para uma formação em Modelagem, seria relevante. Isto é, que as práticas e ações formativas fossem coerentes às propostas e aos objetivos da formação do professor, quando o debate está situado no âmbito da Licenciatura, para que ele tenha condições de planejar e pôr em prática, com segurança, uma atividade de Modelagem.

Compreendemos que esses enfoques dizem muito a respeito da presença da Modelagem e, conforme tem se revelado, sua abordagem na perspectiva da Educação Matemática se mostrou recente nesses cursos. Assim, ainda que em duas componentes o enfoque seja dado à Modelagem na Matemática aplicada, em outros, ainda que as discussões sobre Modelagem nessa perspectiva-Educação Matemática-sejam recentes, elas parecem ter buscado se fundamentar no compartilhamento dessas ideias.

Uma manifestação que corrobora essa afirmação é quando focamos as componentes, no momento em que elas foram inseridas na grade desses cursos. Estamos nos referindo ao que a pesquisa revelou sobre a prática que ocorria em algumas das componentes de Modelagem, quanto ao desenvolvimento de outras atividades como a confecção e ao estudo de materiais didáticos e manipuláveis, diferentemente, do que se caracteriza a Modelagem hoje, na Educação Matemática.

Esse processo de atribuir um novo direcionamento às componentes de Modelagem nos mostra o avanço delas e o esforço que os docentes-formadores tiveram em buscar informações e conhecer "mais de perto" sobre a Modelagem, que a nosso ver, amadureceram-se em meio as discussões no movimento com a própria comunidade. De todo modo, reconhecemos que esse avanço não é linear, pois, é compreensível que essa e também outras pesquisas, estejam cumprindo esse papel, para que novas propostas, 
novas reflexões e futuras ações sejam incorporadas à formação de professores, refletindo nesta mesma transição.

Com vistas a ampliarmos essa compreensão, interpretamos que assim como as componentes, a formação de professores em Modelagem, concomitantemente, passa por um momento de transição e que, portanto, alguns aspectos paradigmáticos ${ }^{6}$ anteriores, podem continuar concorrendo com os novos (Kuhn, 2011). Essa coexistência de paradigmas pode delinear uma nova configuração para as componentes, favorecendo o processo de formação em Modelagem e, em médio e longo prazo, tornar a Modelagem mais recorrente e presente nas propostas pedagógicas nos diferentes contextos de formação, inclusive na continuada. Assim, tornar-se-ia significativo o número de possibilidades de a Modelagem estender-se aos ambientes educacionais.

Todavia, "se o vento virar", e as influências desses paradigmas assumirem outro direcionamento, por exemplo, o da Matemática aplicada, a ruptura com as propostas refletidas pelos educadores matemáticos será inevitável e, transitivamente, os processos de ensino e aprendizagem, bem como, os saberes pedagógicos da Modelagem, poderão perder espaço fazendo-se cumprir outros objetivos, como, talvez restringindo-se ao domínio da matematização do processo de modelar. Mas, a pesquisa registra avanços, novos rumos, pois a busca pela compreensão da Modelagem tem sido destacada pelos docentes-formadores, principalmente, por aqueles que já a conhecem, como uma ânsia pelo acesso, entendimento e discussão das reflexões mais atuais sobre a Modelagem, o que vai de encontro com o paradigma da Modelagem, supracitado.

Considerando esse (futuro) contexto de práticas pedagógicas de Modelagem, a pesquisa nos mostrou que ainda há algumas lacunas na formação em Modelagem. Quando alguns docentes-formadores afirmaram que egressos dos cursos, mesmo tendo experienciado na formação inicial a Modelagem como componente curricular, eles apresentam insegurança em desenvolver atividades de Modelagem, posterior a esse momento da formação ${ }^{7}$, para nós, isso expressa uma lacuna na formação em Modelagem.

Talvez, essa insegurança esteja relacionada ao modo como essas componentes têm se apresentado no contexto da Licenciatura. Se olharmos para as estratégias sugeridas em Barbosa (2001), vislumbrando as diferentes ações de formação em Modelagem, compreendemos que algumas delas, por exemplo, as intervenções em sala de aula, em geral, não têm se mostrado nessa investigação. Por isso, o modo como as componentes têm sido desenvolvidas, indicam para nós ser o fator que talvez justifique as razões dessa lacuna, ao mostrar-nos que parece haver o estudo sobre a Modelagem, em detrimento do seu desdobramento pedagógico.

\footnotetext{
${ }^{6}$ Assumimos aqui o termo "paradigmáticos" como sendo "[...] aquilo que os membros de uma comunidade científica partilham e, inversamente, uma comunidade científica consiste em homens que partilham um paradigma" (Kuhn, 2011, p.221, grifo do autor).

${ }^{7}$ Essas mesmas ideias também foram evidenciadas na pesquisa de Ceolim (2015), quando discute os obstáculos e dificuldades com a implementação de atividades de Modelagem, registrados por egressos, na condição de professores da Educação Básica.
} 
Embora sejam sugestões, as experiências independentes de como elas aconteçam, "[...] voltada também ao seu uso na docência, [...] requer aprendizados relacionados ao fazer Modelagem, à preparação de situações de Modelagem e à aplicação dessas situações em aulas da Educação Básica" (Silva \& Dalto, 2011, p.182), ou simulações dessas práticas, de modo que elas possam ser vivenciadas pelos estudantes sob dois domínios, na condição de alunos e, na de professores (Barbosa, 2004), para que cumpra, minimamente, esse desdobramento pedagógico da formação em Modelagem.

Conforme já indicamos, em apenas uma das componentes analisadas, a reflexão sobre a docência em Modelagem se mostra ausente. Noutro, essa abordagem é realizada apenas no início e no fim da componente, e ao que indica, ocorrer de modo aligeirado. Já nos outros seis, o encaminhamento da prática pedagógica de Modelagem, parece ser prioridade na e para a formação. No movimento de compreendermos sobre esses diferentes enfoques dados à ela, entendemos que esses enfoques propiciam diferentes aprendizagens teórico-práticas, e, de acordo com suas especificidades, as habilidades e as limitações para adoção (ou não) da Modelagem, por exemplo, na prática pedagógica dos futuros professores, tendem a ser fortalecidos por esses enfoques que configuram as ações didático-pedagógicas nessas componentes.

Nesse sentido, ao focarmos o que se revela do contexto dessa investigação as componentes de Modelagem - admitindo-as segundo os enfoques supracitados, entendemos que, naqueles seis cursos em que a prática formativa se orienta nos pressupostos da Educação Matemática, o modo como se pensa a formação em Modelagem, e consequentemente, as habilidades do professor quando "formado" para adoção de práticas de Modelagem, tendem a se destacarem, perante aos outros dois cursos, cujas práticas admitem outras conotações. Contudo, não podemos desconsiderar outros fatores que também são determinantes, os quais podem ser definidores do sucesso e/ou fracasso do processo formativo, bem como, do trabalho com a Modelagem, pois, essas discussões também podem ser fruto do curto espaço de tempo que a eles é destinado para compreensão da Modelagem como atividade pedagógica.

Sobre essas reflexões e considerando o que temos discutimos até aqui, direcionamos o debate para o questionamento: "então, por que concentrar os estudos sobre Modelagem em um momento, já que há alguns indícios de fragilidade quanto a sua configuração como componente?".

Primeiramente, nossa reflexão sobre o que se revela, indica a necessidade de reestruturação curricular nas grades desses cursos para que a Modelagem deixe de ser episódica. Por um lado, essa presença como componente revela o significado da Modelagem e o fortalecimento/reconhecimento que ela teve como tendência da Educação Matemática, pois, o modo como ela tem se configurado revela contribuições como componente ${ }^{8}$. Mas, por outro, condiciona-nos a refletir sobre os modos de como ela tem sido implementada no âmbito dos cursos.

\footnotetext{
${ }^{8}$ Fazemos aqui um adendo de que essa emergência de um espaço específico para o debate e reflexão sobre os aspectos teórico-prático-metodológicos de conhecimentos que objetivam a prática pedagógica dos futuros
} 
A pesquisa nos mostra que ela, a componente curricular de Modelagem, pode se consolidar como um espaço para dar subsídio à compreensão das práticas com Modelagem quando desenvolvidas como metodologia, em outras componentes. Sem dúvida, para que os estudantes possam compreender as aplicações e seus desdobramentos para o ensino da Matemática, ela solicita extrapolar os limites disciplinares e se fazer presente em todo o curso ou, pelo menos em boa parte dele. Assim, de uma forma ou de outra, essa interpretação mostra que a superação do modelo da Licenciatura se impõe para o fortalecimento não só da Modelagem, como de outras tendências da Educação Matemática, no próprio solo da formação, conforme já refletiram Biembengut e Faria (2009), de que a “[...] estrutura educacional com currículo partido em várias disciplinas, [...], sem dúvida, é a principal dificuldade para tornar a modelagem matemática um método de ensino e aprendizagem em sala de aula" (2009, p.10.102).

Refletimos assim, que a configuração em modelos disciplinares pode estar contribuindo, em certo sentido, para dificultar a inserção de maneira mais efetiva da implementação dessas tendências metodológicas na prática pedagógica. E, ao refletirmos sobre a Modelagem, ela se mostra incomensurável ao modelo disciplinar imposto como Licenciatura, pois, considerando as próprias características que a prática de Modelagem solicita, como, a necessidade de se reconfigurar o papel da ação docente e sua interação com os estudantes elas, por si só, já expressam uma divergência aparente, uma vez que elas, enquanto práticas formativas sempre extrapolam os limites disciplinares (Klüber, 2012a).

Talvez, um modo de vislumbrarmos novos horizontes para a formação em Modelagem, que também emerge dessa pesquisa, seria a configuração de grupos de estudos pedagógicos sobre Modelagem no âmbito das instituições e, a presença maior de docentes que compartilham das ideias da Educação Matemática. Segundo eles, há docentes-formadores que têm interesse em desenvolver atividades de Modelagem em outras componentes, o que, para nós, já indica uma melhoria nas relações entre as componentes de Matemática e as de Ensino/Pedagógicas. Nesse contexto, compreendemos que o desenvolvimento de trabalhos e práticas em parceira poderia ser um modo pelo qual os futuros professores teriam a oportunidade de, pedagogicamente, vivenciarem a Modelagem. Assim, poderiam vivenciar tanto o desenvolvimento das etapas, fases, e/ ou momentos da Modelagem, quanto, apropriarem-se dos conhecimentos específicos abordados na componente.

Essa discussão se sustenta na experiência que alguns desses docentes-formadores tiveram com outros colegas de trabalho de outras componentes, nesses cursos. Segundo eles, muitas vezes, alguns desses colegas acabavam desenvolvendo atividades de Modelagem, ou atividades bem próximas do que seria a Modelagem e não sabiam que estavam desenvolvendo a prática pedagógica valendo-se dela. Nesse sentido, entendemos que, a organização desses grupos para o debate sobre Modelagem, assim como, para as

professores - a construção de ambiente para formalizarem-se as experiências formativas, seja de Modelagem ou não - se mostram fundamentais para a formação. Porém, o modo como elas podem ser conduzidas e o papel que elas exercem na totalidade dessa etapa (inicial) da formação, há de ser refletida. 
demais tendências em Educação Matemática, poderia configurar espaços de reflexões, que auxiliariam esses docentes-formadores no planejamento de ações, socializações e reflexões sobre as práticas desenvolvidas na formação inicial, permitindo-os reconhecêlas. Além de, viabilizarem-se espaços/tempos de aprendizagens sobre as tendências metodológicas, de modo mais efetivo, no âmbito da Licenciatura.

\section{CONSIDERAÇÕES FINAIS}

Como remate desse debate, as discussões inerentes à pesquisa mais ampla que desenvolvemos nos mostram a importância de realizarmos estudos que diagnosticam um contexto, no intento de se refletir sobre ele e, talvez, apontarmos caminhos para minimizar as limitações e os aspectos que são intransigentes na sua constituição. Nesse sentido, a investigação sobre a presença da Modelagem no contexto da formação inicial de professores de Matemática, possibilitou-nos refletir sobre o seu papel, enquanto componente curricular, a partir do olhar sob o par fenômeno/percebido que se mostrou, ao focarmos as Licenciaturas em Matemática das instituições universitárias estaduais do Estado do Paraná.

Dentre os diferentes aspectos que se mostraram, as "Compreensões sobre as disciplinas de Modelagem Matemática”, nos permitiram refletir sobre alguns aspectos de ordem mais estruturais, bem como, alguns elementos que nos auxiliaram na compreensão dessas componentes e, transitivamente, sobre a formação em Modelagem que elas propiciam.

Para além do que discutimos nesse texto, porém, de modo articulado, pode parecer desnecessária a presença de uma componente curricular de Modelagem, configurada na formação inicial. No entanto, o debate que aqui estabelecemos nos conduz a refletirmos sobre as componentes, quanto ao que se mostrou de sua configuração e, não a defesa de sua extinção. Na verdade, fomos desnudando aspectos que reafirmam a importância de voltarmos nossos olhares para a formação inicial em Modelagem, no sentido de dar a ela (à componente) visibilidade e justificar tanto sua permanência, como os seus sentidos no contexto da formação do professor.

Queremos dizer que as unidades expressas, indicaram a importância da implementação não só da Modelagem, mas, de todas as tendências em Educação Matemática no âmbito dos cursos, perpassando ainda pelas diferentes componentes. Contudo, ao nosso entendimento, para que isso se torne efetivo no âmbito da formação inicial de professores de Matemática, registramos a necessidade de mudanças estruturais nas grades dos cursos para que ela (por exemplo, a Modelagem), possa permear todas as outras componentes e deixe de ser episódica como tem ela sido apresentada.

Apesar da defesa dessas ideias, conforme já discorremos, pode parecer contraditório concentrá-la em apenas um momento dessa etapa da formação. Mas, as unidades destacaram sua relevância e necessidade, como componente específica, pois, pode ser um espaço/tempo oportuno para que os futuros professores ressignifiquem suas compreensões 
acerca da Modelagem e transcenda-as para o contexto da prática pedagógica em sala de aula.

Para além dessa configuração, no sentido de perpassar as diferentes componentes, reconhecemos a importância de esses contextos de práticas reflexivas na e para a formação do professor, tendo em vista a socialização e debates de prática e teorização sobre Modelagem, de modo que venham configurar outros contextos, por exemplo, em projetos de extensão, projetos de iniciação à docência, práticas vinculadas ao Estágio Curricular Supervisionado, bem como, noutras componentes curriculares que se orientam e trabalham com Modelagem.

\section{AGRADECIMENTOS}

O trabalho de Mestrado foi realizado com apoio parcial da Coordenação de Aperfeiçoamento de Pessoal de Nível Superior - Brasil (CAPES) - Código de Financiamento 001.

\section{REFERÊNCIAS}

Barbosa, J. C. (2001) Modelagem Matemática e os professores: a questão da formação. Bolema: Boletim de Educação Matemática, Rio Claro, 14(15), 5-23.

Barbosa, J. C. (2004) As relações dos professores com a Modelagem Matemática. Anais do Encontro Nacional de Educação Matemática, 8., Recife, 1-11.

Barbosa, J. C. (2007) Sobre a pesquisa em Modelagem Matemática no Brasil. Anais da Conferência Nacional de Modelagem Matemática na Educação Matemática, 5., Ouro Preto, 82-103.

Barbosa, J. C. (2011) Prefácio. In: Almeida, L. M. W. de, Araújo, J. de L., \& Bisognin, E. (Org.) Práticas de Modelagem Matemática na Educação Matemática: Relatos de Experiências e Propostas Pedagógicas. Londrina/PR: Eduel.

Bicudo, M. A. V. (2011) Pesquisa qualitativa segundo a visão fenomenológica. São Paulo/SP: Cortez.

Biembengut, M. S., \& Faria, T. M. B. (2009) Modelagem matemática na formação de professores: possibilidades e limitações. Anais do Congresso Nacional de Educação, 9., Curitiba, 10095-10109.

Ceolim, A. J. (2015) Modelagem matemática na educação básica: obstáculos e dificuldades apontados por professores (151f.). Tese de doutorado, Educação, Programa de Pós-Graduação em Educação. Universidade Federal de São Carlos, São Carlos.

García, C. M. (1999) Formação de professores: para uma mudança educativa. Portugal: Porto Editora.

Garnica, A. V. M. (1997) Algumas notas sobre pesquisa qualitativa e fenomenologia. Interface - comunicação, saúde, educação, 1(1),109-122.

Klüber, T. E. (2012a) Uma metacompreensão da Modelagem Matemática na Educação Matemática (396f.) Tese de doutorado, Educação Científica e Tecnológica, Programa de 
Pós-graduação em Educação Científica e Tecnológica. Universidade Federal de Santa Catarina, Florianópolis.

Klüber, T. E. (2012b) (Des)encontros entre a modelagem matemática na educação matemática e a formação de professores de matemática. Alexandria: Revista de Educação em Ciência e Tecnologia, 5(1), 63-84.

Klüber, T. E. (2016) A Pesquisa e a Prática em Modelagem Matemática na Educação Matemática: Um Debate. Anais do VII Encontro Paranaense de Modelagem na Educação Matemática. 7., Londrina, UEL/ UTFPR, 21-30.

Klüber, T. E.; Tambarussi, C. M.; Loureiro, D. Z.; Wichnoski, P.; Oliveira, W. P. (2015) Rumos e avanços da Modelagem Matemática na Educação Matemática Brasileira: Um olhar sobre a pesquisa a partir dos resumos do V SIPEM. Indagatio Didactica, 7(1), $80-95$.

Kuhn, T. S. (2011) A estrutura das revoluções científicas. 10ª . ed. São Paulo/SP: Perspectiva.

Malheiros, A. P. dos S.; Almeida, L. M. W. de; Klüber, T. E. (2015) Pluralidades e debates da Modelagem Matemática na Educação Matemática: concepções, tendências e áreas. Anais da IX CNMEM - Conferência Nacional sobre Modelagem na Educação Matemática, 9., São Carlos, UFSCar, 1-11.

Oliveira, W. O. (2016a) Referências de Modelagem Matemática na formação inicial de professores de Matemática: um debate sobre a formação. Anais do XII Encontro Nacional de Educação Matemática, 12., São Paulo, UNICSUL, 1-13.

Oliveira, W. P. (2016b) Modelagem Matemática nas licenciaturas em Matemática das universidades estaduais do Paraná. (155 f.) Dissertação de mestrado, Educação, Programa de Pós-graduação em Educação, Universidade Estadual do Oeste do Paraná, Cascavel. Penteado, M. G. (2001) Implicações para a prática docente. In Borba, M. C., \& Penteado, M. G. (Org.) Informática e Educação Matemática. Belo Horizonte/MG: Autêntica.

Silva, D. K. Da, \& Dalto, J. O. (2011) Modelagem matemática na formação de professores: compartilhando uma experiência. In Almeida, L. M. W De, Araújo, J. L., \& Bisognin, E. (Org.) Práticas de Modelagem Matemática na Educação Matemática: Relatos de Experiências e Propostas Pedagógicas. Londrina/PR: Eduel. 